\title{
Electrical Properties of Sand-Clay Mixtures Containing Trichloroethylene and Ethanol
}

\author{
J.J. Roberts, and D. Wildenschild
}

This article was submitted to the Symposium for the Application of Geophysics to Engineering and Environmental Problems, Las Vegas, Nevada, February 10-14, 2002

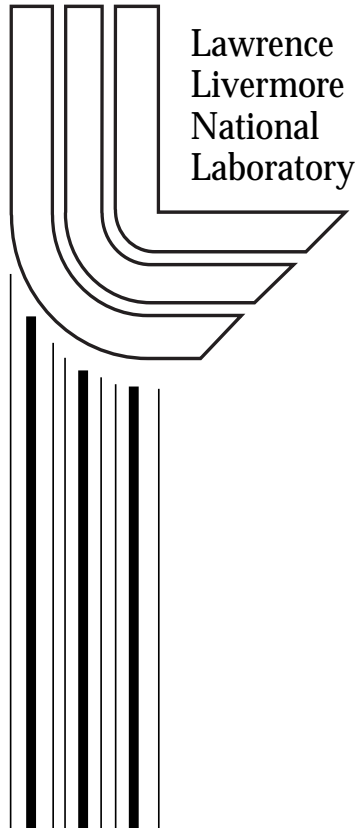

December 4, 2001 


\section{DISCLAIMER}

This document was prepared as an account of work sponsored by an agency of the United States Government. Neither the United States Government nor the University of California nor any of their employees, makes any warranty, express or implied, or assumes any legal liability or responsibility for the accuracy, completeness, or usefulness of any information, apparatus, product, or process disclosed, or represents that its use would not infringe privately owned rights. Reference herein to any specific commercial product, process, or service by trade name, trademark, manufacturer, or otherwise, does not necessarily constitute or imply its endorsement, recommendation, or favoring by the United States Government or the University of California. The views and opinions of authors expressed herein do not necessarily state or reflect those of the United States Government or the University of California, and shall not be used for advertising or product endorsement purposes.

This is a preprint of a paper intended for publication in a journal or proceedings. Since changes may be made before publication, this preprint is made available with the understanding that it will not be cited or reproduced without the permission of the author.

This report has been reproduced directly from the best available copy.

Available electronically at http://www.doc.gov/bridge

Available for a processing fee to U.S. Department of Energy

And its contractors in paper from

U.S. Department of Energy

Office of Scientific and Technical Information

P.O. Box 62

Oak Ridge, TN 37831-0062

Telephone: (865) 576-8401

Facsimile: (865) 576-5728

E-mail: reports@adonis.osti.gov

Available for the sale to the public from

U.S. Department of Commerce

National Technical Information Service

5285 Port Royal Road

Springfield, VA 22161

Telephone: (800) 553-6847

Facsimile: (703) 605-6900

E-mail: orders@ntis.fedworld.gov

Online ordering: http://www.ntis.gov/ordering.htm

\section{OR}

Lawrence Livermore National Laboratory

Technical Information Department's Digital Library

http://www.llnl.gov/tid/Library.html 


\title{
ELECTRICAL PROPERTIES OF SAND-CLAY MIXTURES CONTAINING TRICHLOROETHYLENE AND ETHANOL
}

\author{
Jeffery J. Roberts and Dorthe Wildenschild* \\ Lawrence Livermore National Laboratory, Livermore, CA 94551 \\ *Now at Technical University of Denmark, Lyngby, Denmark
}

\begin{abstract}
A series of laboratory experiments, including the measurement of electrical properties and permeability, were performed on carefully characterized sand-clay mixtures. Different mixtures and configurations of quartz sand and 0 to $10 \%$ Na-montmorillonite clay were investigated using solutions of $\mathrm{NaCl}, \mathrm{CaCl}_{2}$, and deionized water. Samples containing $10 \%$ distributed clay were also studied using fluids containing 20 and $500 \mathrm{ppm}$ trichlorethylene (TCE). Electrical properties were measured at frequencies between $10^{6}$ and $10^{-2} \mathrm{~Hz}$ using the four-electrode method and $\mathrm{Ag}-\mathrm{AgCl}$ inner electrodes on saturated samples at room temperature and $412 \mathrm{kPa}$ confining pressure, corresponding to a soil depth of 15 to $20 \mathrm{~m}$. Our results show that the addition of TCE has a small effect on electrical resistivity, with resistivity increasing with the addition of TCE. The influence of TCE on the electrical properties was most prominent in plots of loss tangent as a function of frequency. A loss tangent peak occurred at $\sim 200 \mathrm{~Hz}$. The height of the peak and the peak frequency both decrease with the addition of TCE. Further experiments were performed on samples containing a distinct clay layer parallel to current flow. Electrical properties were measured on water saturated samples and as a mixture of ethanol and water (80:20) was flowed through the sample. Resistivity increased by about a factor of four as the ethanol mixture replaced the water solution. Non-destructive x-ray imaging of the sample at various stages of dewatering indicates a decrease in the thickness of the clay layer with increasing number of pore volumes of ethanol-water flowed. Our results showed that electrical measurements are a useful tool for characterizing porous rocks and soils and that it is feasible to remotely detect the presence and follow the transport of contaminants such as TCE in the subsurface.
\end{abstract}

\section{Introduction}

\subsection{Background}

Electrical measurements are a useful non-destructive tool for characterization of porous rocks and soils. Conduction of electricity through porous media occurs primarily by movement of ions through the bulk saturating electrolyte. In addition, conduction takes place as adsorbed ions move along the surfaces of pores and cracks. Thus, the conductivity of a porous medium is related to microstructural properties such as porosity, pore geometry, and surface morphology of the mineral grains lining the pores, as well as the dielectric properties of the mineral grains and pore fluid. Electrical conduction is also a function of the prevailing fluid saturation. For brine-saturated porous materials Archie (1942) proposed the following relationship between bulk and fluid conductivities:

$$
\rho_{\text {bulk }}=\rho_{\text {fluid }} a \varphi^{m}
$$

where $\rho_{\text {bulk }}$ is the electrical conductivity of the porous medium, $\rho_{\text {fluid }}$ is the electrical conductivity of the saturating fluid, $\varphi$ is the porosity, and $a$ and $m$ are parameters that are supposed to be constant for a certain type of rock. The ratio $\rho_{\text {fluid }} / \rho_{\text {bulk }}$ is the formation factor F. In equation (1) it is assumed that the contribution of surface conduction to the bulk conduction is negligible. When bulk conduction is important, Archie's law has to be modified (Johnson et al., 1986; Waxman and Smits, 1968; Sen et al., 1988; Sen and Goode, 1992). Instead of the pure proportionality between $\rho_{\text {bulk }}$ and $\rho_{\text {fluid, }}$ we obtain a linear dependence with an intercept on the ordinate axis. Johnson et al. (1986) defined a length parameter 
$\Lambda$, which is a weighted volume-to-surface-area ratio (a measure of the dynamically interconnected pore size) defined as

$$
\frac{\Lambda}{2}=\frac{\left.\int E(r)\right|^{2} d V_{p}}{\left.\int E(r)\right|^{2} d S}
$$

$\mathrm{E}(\mathrm{r})$ is the electric potential field at point $\mathrm{r}, \mathrm{Vp}$ is the pore volume and $\mathrm{S}$ is the surface area, i.e. the poresolid interface. $\Lambda$ is a parameter (with units of length) characteristic of the geometry of the porous medium and is thus transferable from one experiment to another for a specific medium. This relation is valid for materials where the (insulating) grains are coated with appreciable amounts of clay minerals (Johnson et al., 1986). When dry clays are saturated with brines the counter ions, which usually balance out charged impurities by bonding to their external surfaces, hydrate and become mobile within a layer. Surface conduction due to these counter ions then acts in parallel with the ionic conduction associated with the brine. For relatively high-salinity pore fluids, a linear relationship was derived (Johnson et al., 1986):

$$
\rho_{\text {bulk }}=\frac{1}{F}\left(\rho_{\text {fluid }}+\frac{2 \Sigma_{s}}{\Lambda}\right)
$$

where $\Sigma_{\mathrm{s}}$ is the surface conductivity. When $\rho_{\text {fluid }}$ and $\rho_{\text {bulk }}$ are plotted on a linear scale, the slope equals the reciprocal of the formation factor $F$, and the intercept with the ordinate axis $b=2 \Sigma_{s} / F \Lambda$.

\subsection{Previous Work}

Previous work by Wildenschild et al., $(1999,2000)$ demonstrated the influence of various microstructural properties (such as clay content and configuration) on the electrical properties. They determined formation factors, $\Lambda$ parameters, and surface conductances $\Sigma_{\mathrm{s}}$ for a number of different configurations containing 0 to $10 \%$ clay. The arrangements included dispersed mixtures, discrete clay clusters and arrangements of distinct layers of clay in the sand matrix. They found the relationship (eqn. 3) suggested by Johnson et al. (1986) to describe conduction for a wide range of parameters including fluid salinity, clay content, and surface conductance. In this study we present additional work on samples studied by Wildenschild et al. $(1999 ; 2000)$ using pore fluids that contain small amounts $(<500 \mathrm{ppm})$ of TCE or ethanol/water mixtures.

Work on clay bearing materials containing organic compounds has been performed previously and some of this worked will be reviewed briefly here. Olhoeft and King (1991) reported complex resistivity measurements on synthetic clay-toluene mixtures. They found a resistivity increase $(\sim 10$ to $30 \%)$ and a larger (negative) phase angle for samples containing up to $20 \%$ toluene. The resistivity difference was greatest at frequencies below $\sim 100 \mathrm{~Hz}$ and the phase difference was greatest between 1 and $100 \mathrm{~Hz}$. Work by Chan et al. (2000) on sand-clay mixtures shows that non-contaminated samples show little frequency dependence and follow Archie's law. When TCE was present in a $100 \%$ sand sample they found that Archie's law did not apply. Re-saturating the contaminated sample with brine produced anomalous results attributed to incomplete removal of TCE from the sample.

A comprehensive set of experiments on prepared and natural clay-bearing samples was performed by Jones (1997) as part of his thesis work. He measured complex electrical properties from $10^{-3}$ to $10^{6} \mathrm{~Hz}$ while varying the solution type and concentration. Measurements were performed on samples containing a variety of organic contaminants including TCE, tetrachloroethylene, ethylene glycol, and phenol. Changes in the non-linear character of the complex electrical response were observed that were attributable to chemical reaction between the clay and the organic contaminants. Spectral alterations were observed to take place for as much as one month at which point equilibrium had not yet been established. These changes in non-linear response are suggested as a means of locating contaminated regions using field EM data. 


\section{Experimental Details}

\subsection{Sample Preparation and Characterization}

We used a pure silica sand (F-50 Ottawa sand from U.S. Silica) and a Na-montmorillonite (Wyoming bentonite) to build the samples. The Ottawa sand has grain sizes between 74-420 microns, a median diameter $\left(\mathrm{d}_{50}\right)$ of 273 microns and a particle density of $2.66 \mathrm{~g} / \mathrm{cm}^{3}$. The samples were packed in 2-inch diameter heat shrink tubing with sintered Hasteloy frits at both ends that provided support, allowed fluid flow, and served as current electrodes. Sample height was 1.5 inches and AgCl coated silver wire electrodes were positioned in the casing 0.25 inches from either end of the sample using additional heat shrink material as spacing. The electrochemically coated $\mathrm{Ag}-\mathrm{AgCl}$ wires served as potential electrodes. Platinum electrodes were unsuitable because of hydrolysis at the metal-water interface, causing unreliable measurements. The AgCl-coated wires alleviated this problem by providing a means of ionic exchange with the saturating solution.

Once the sand/clay was packed between frits the tubing was heated and would subsequently shrink to rigidly support the unconsolidated sample. The dispersed clay samples were packed from dry mixed sand and clay. In the case of the parallel sample, dry sand was packed around the vertical clay layer, which then was in contact with both end frits.

\subsection{Pore Fluids}

The samples were saturated with saline fluids of varying concentration, ranging from $0.0005 \mathrm{~N}$ to $0.75 \mathrm{~N}$ of $\mathrm{CaCl}_{2}(0.05$ to $64 \mathrm{mS} / \mathrm{cm})$. Electrical measurements were also made using de-ionized water. Results are reported in Wildenschild et al. (2000). Solutions of $600 \mu \mathrm{S} / \mathrm{cm} \mathrm{NaCl}(\sim 0.0035 \mathrm{M})$ were prepared containing 0,20 , and $500 \mathrm{ppm}$ TCE. These solutions were used as pore fluids in a $10 \%$ clay dispersed sample. The solubility limit for TCE in water at room temperature $\left(20^{\circ} \mathrm{C}\right)$ is about $1099 \mathrm{ppm}$. Additional experiments were performed with an 80:20 mixture of ethanol and distilled water. This fluid was flowed through the sample containing a parallel clay layer.

\section{Apparatus and Measurement Procedures}

The experimental setup consists of 4 major components: the sample, the sample holder with pressure controls, the electrical measurement system, and the fluid flow system (Figure 1; Wildenschild et al., 2000). The sample is placed in a Hassler sleeve used to control pore pressure. The Hassler sleeve is placed between insulating Delrin end caps and is held in place by applied end-load and in-load pressures using air actuated cylinders. The various loads ensure that the sample is hydraulically sealed in the holder, i.e. sidewall flow is avoided and also provides for simulating shallow burial. We used endload, in-load, and confining pressures of $60 \mathrm{psi}(418 \mathrm{kPa})$ in all experiments. The end caps have openings for fluid inlet and outlet and for the electrical input and output voltage leads.

\subsection{Electrical Measurements}

As the various fluids were pumped through the samples, frequency-dependent electrical properties were measured using the four-electrode method (Olhoeft, 1985). Impedance magnitude, |Z|, phase angle $\phi$, electrical resistance $\mathrm{R}$, and capacitance $\mathrm{C}$ were measured with an HP4284A LCR meter during flow and at hydraulic equilibrium. Complex impedance spectra over a wider range of frequencies $(10 \mathrm{mHz}$ to $1 \mathrm{MHz})$ were measured using a Solartron 1260A impedance analyzer.

The complex impedance consists of a real and imaginary part and is given by

$$
Z^{*}=Z^{\prime}-j Z^{\prime \prime}
$$

where $Z$ ' represents the real impedance, $Z$ " the imaginary impedance and $j=\sqrt{ }-1$. The resistivity is the impedance, or resistance, taking into account the sample geometry

$$
\rho^{*}=Z^{*} A / l
$$




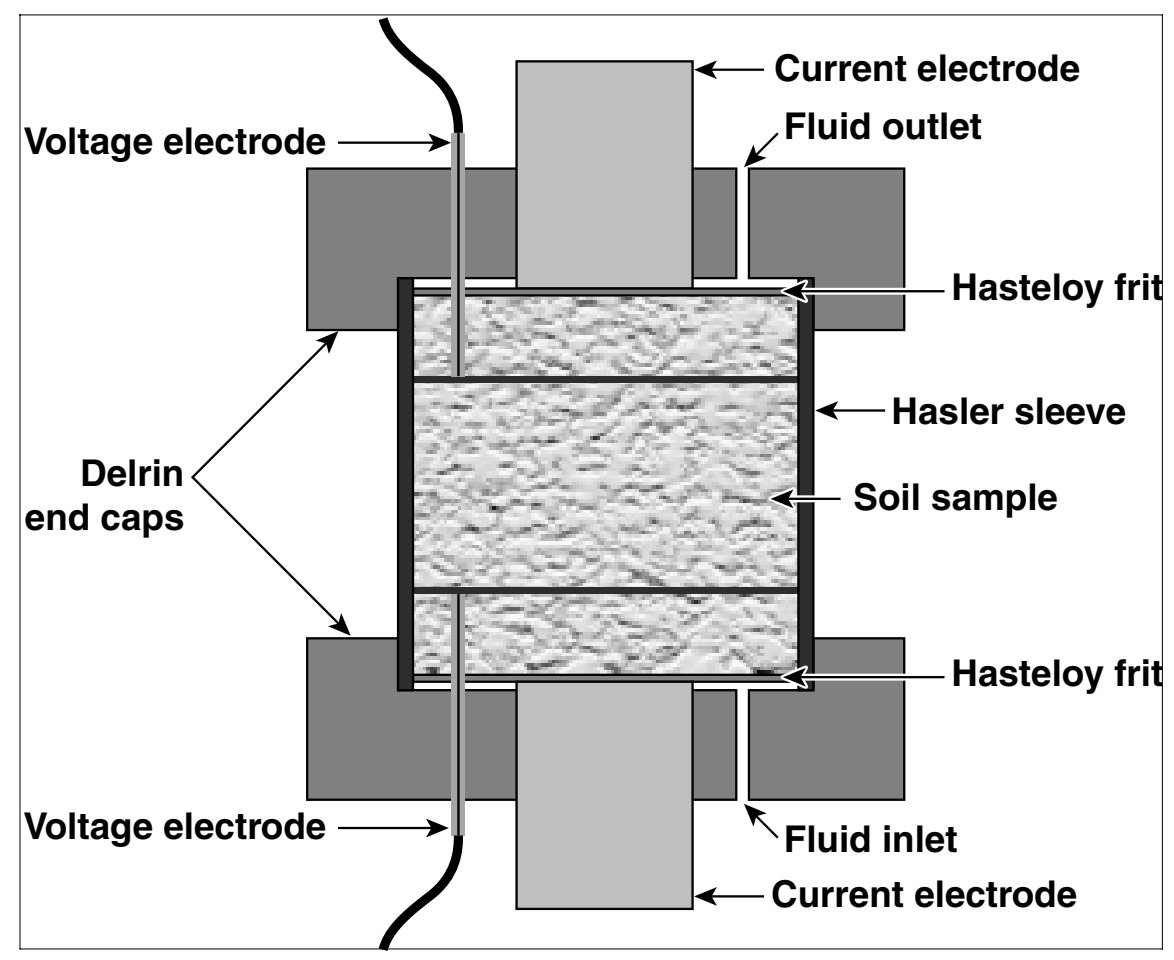

Figure 1. Experimental apparatus for confining pressure, fluid flow, and impedance measurements.

Electrical conductivity $\sigma$ is the reciprocal of the resistivity. The dielectric permittivity $\kappa$ is related to the impedance by

$$
\kappa^{*}=\kappa^{\prime}-j \kappa^{\prime \prime}=\left(j \omega C_{0} Z^{*}\right)^{-1}
$$

where $\kappa^{*}$ is the dielectric permittivity divided by the permittivity of free space, $\varepsilon 0$, and has a value of $8.854 \times 10^{-12} \mathrm{~F} / \mathrm{m}$, and $C_{0}$ is the capacitance of the empty cell in a vacuum $\left(C_{0}=\varepsilon_{0} A / l\right)$. The loss tangent $\tan \delta$ is defined as

$$
\tan \delta=\frac{\sigma^{\prime}-\varepsilon^{\prime \prime} \omega}{\sigma^{\prime \prime}+\varepsilon^{\prime} \omega} \approx \frac{\sigma^{\prime}}{\sigma^{\prime \prime}} .
$$

The loss tangent approximates the conductivity ratio for small angular frequency $\omega$ where conduction currents dominate displacement currents (Ward and Hohmann, 1987). The loss tangent is also called the dissipation factor and is a measure of the energy transferred to the material from the electric field, primarily through friction associated with the movement of ions and dipoles.

\section{Results and Discussion}

\subsection{Electrical Measurements on Samples Containing TCE}

The electrical impedance of the $10 \%$ dispersed bentonite sample changes with the amount of TCE present. Figure 2a plots the imaginary versus real impedance and shows an increase in the resistance with increasing TCE. Two impedance arcs are visible and both arcs widen, indicating a larger resistance, with an increase in the amount of TCE. Figure $2 \mathrm{~b}$ shows the real and imaginary parts of the impedance plotted as a function of frequency. The critical frequency, the frequency where the minimum phase angle occurs (Dias, 2000), is lower by a factor of about 2.5 for the 500 ppm TCE sample compared to the clean sample. This is most readily observed in Figure $2 \mathrm{a}$ by noting where the imaginary impedance comes closest to the real axis. 

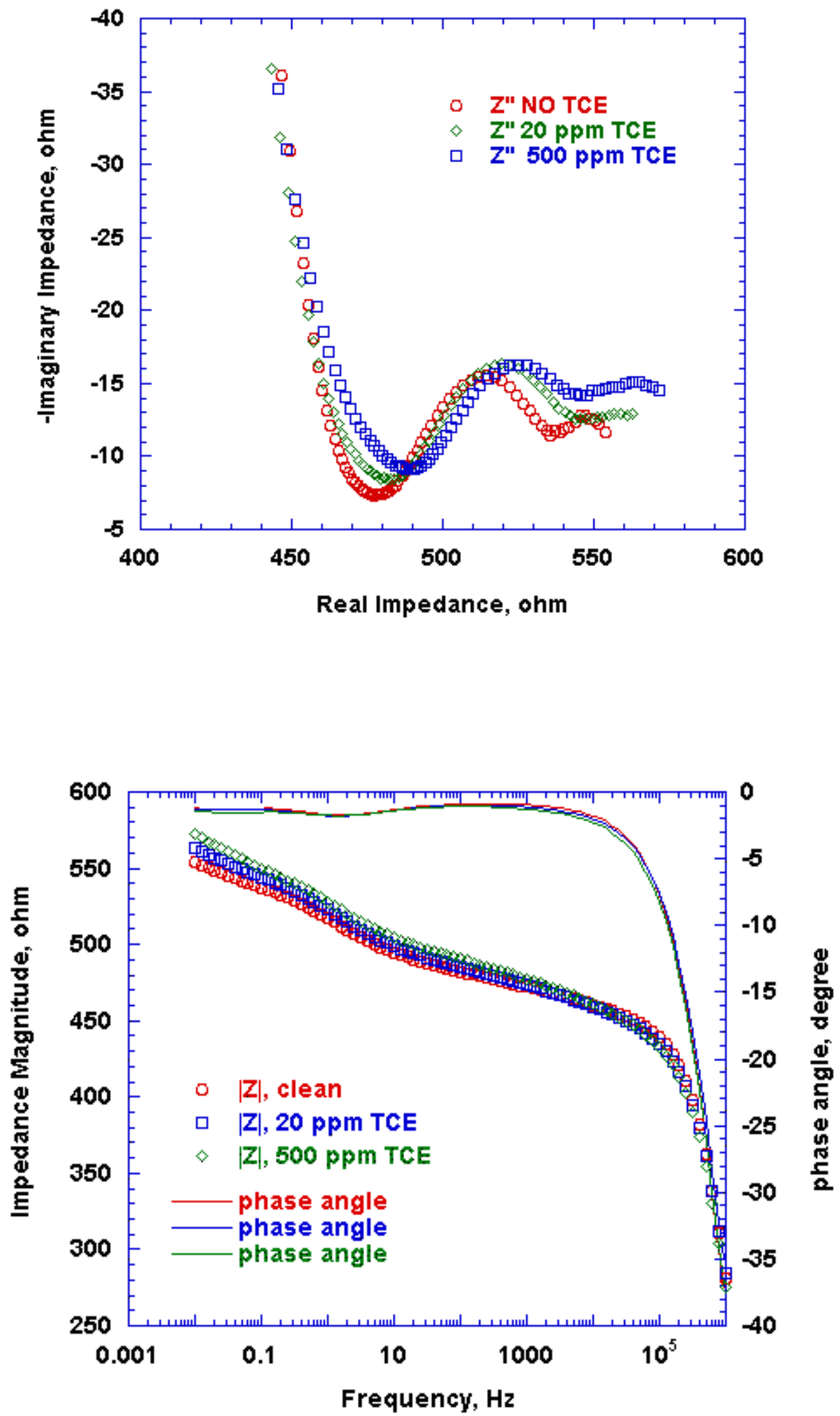

Figure 2. (a) Imaginary vs real impedance, (b) impedance magnitude and phase angle vs frequency. 
The loss tangent for the three experiments is plotted in Figure 3. We found that the differences in electrical response are most apparent in this type of plot. The most prominent feature is the loss peak that occurs between 100 and $1000 \mathrm{~Hz}$ that decreases in magnitude and shifts to a slightly lower frequency with the addition of TCE. The frequency of the loss tangent peak coincides with the critical frequency.

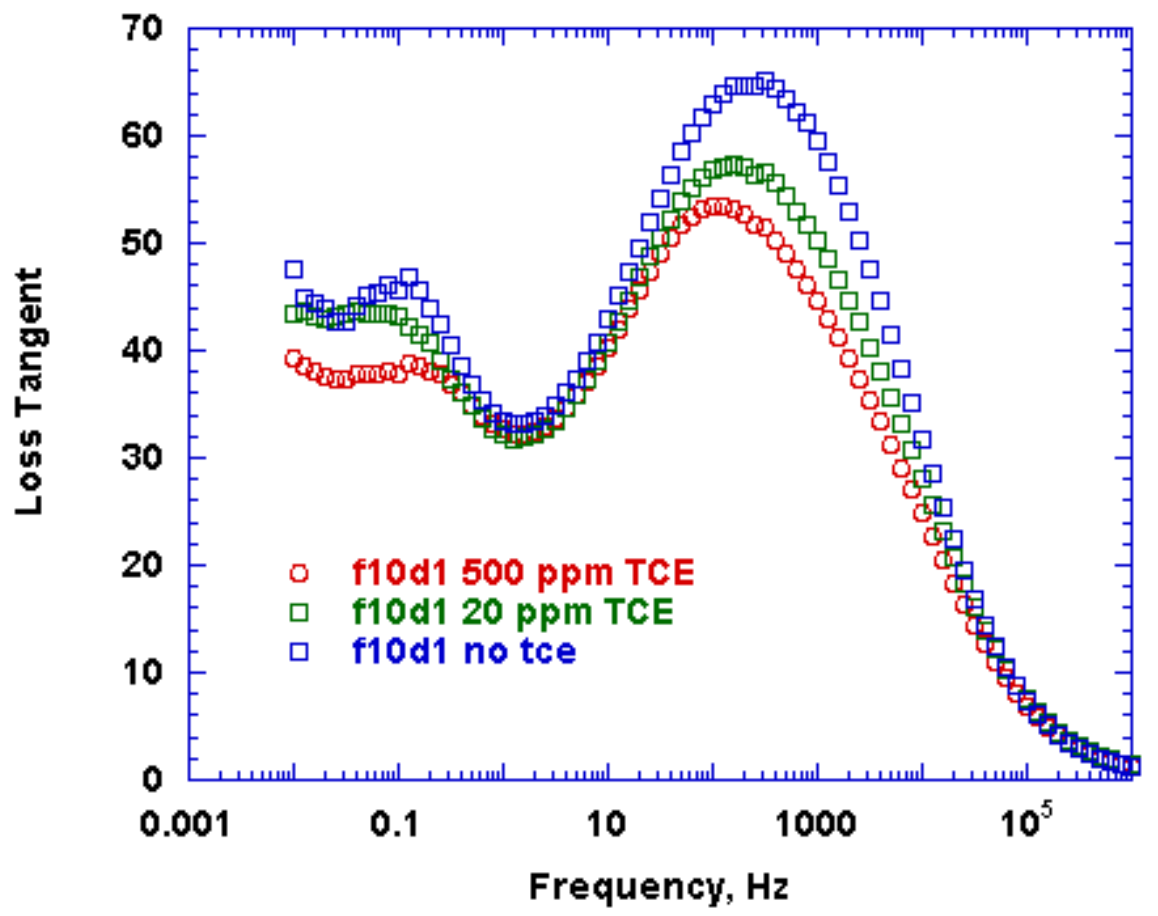

Figure 3. Loss tangent vs frequency for the three experiments.

The highest frequency impedance arc increases resistance about 5\% for the $500 \mathrm{ppm}$ TCE sample compared to the clean sample. Since TCE is a resistive fluid compared to the $\mathrm{NaCl}$ solution we expect an increase in resistance as the conductive fluid is displaced, but the change in resistance compared to the amount of TCE indicates an additional mechanism. The magnitude of the loss tangent peak decreases by about $17 \%$ with the addition of $500 \mathrm{ppm}$ TCE. Possible contributors to this effect are a change in the exchangeability of the clay because of the TCE or other electrochemical reactions. Additional study is required to identify the cause. Nevertheless, it may be possible to use this information to locate small amounts of contamination in field sites using EM methods (Jones, 1997).

\subsection{Electrical Measurements on Samples Containing Ethanol}

Of interest in environmental remediation is the behavior of clay bearing soil that contains ethanol. Ethanol dewaters clays and causes them to contract. One problem with pump and treat remediation of clay-bearing soils containing organic contaminants is the amount of time it takes for the contaminant to diffuse to a permeable flow channel. One idea is that ethanol will not only dewater clay but cause microcracks in clay layers providing a shorter pathway for the migration and removal of contaminants. We have measured the electrical properties of a sand-clay sample containing a clay layer that is parallel to the direction of fluid flow and electrical measurement. Measurements were made using distilled water and $\mathrm{CaCl}_{2}$ solutions ranging from $0.005 \mathrm{~N}$ to $0.4 \mathrm{~N}$ (Wildenschild et al., 2000) and as an 80:20 
ethanol-water mixture was flowed through the sample at a rate of $5 \mathrm{~mL} /$ hour (the conductivity of the ethanol-water mixture is $\sim 0.76 \mu \mathrm{S} / \mathrm{cm}$ ).

The conductivity of the parallel clay sample increased as the salinity of the $\mathrm{CaCl}_{2}$ fluid was increased, but not as strongly as other samples with 10\% dispersed clay (Wildenschild et al., 2000). One reason for this is that the parallel clay sample had the highest surface conductance of all the types of samples studied $(2.45 \mu \mathrm{S})$ and was fairly conductive even for the most dilute solutions. The loss tangent for the dispersed-clay experiments displays more variation than the loss tangent for the parallel-clay layer samples (Figure $4 \mathrm{a}$ and $\mathrm{b}$ ). The loss tangent for the dispersed-clay sample increases with increasing salinity and shows more peaks or peaks shifted to lower frequency. These low frequency peaks occur between 110 and $0.1 \mathrm{~Hz}$ and are absent for the samples saturated with distilled water and the ethanol-water mixture.

As the ethanol mixture was flowed through the sample the impedance increased by about a factor of 4 over the $0.022 \mathrm{~N} \mathrm{CaCl}_{2}$ solution impedance. Additional flow of the ethanol-water mixture to up to 10 pore volumes continued to increase the impedance. After 15 pore volumes the fluid flow was stopped and impedance decreased with time. The loss tangent shows a single peak centered near $500 \mathrm{~Hz}$ for the ethanol-water saturated sample. With additional flow the peak first becomes lower in magnitude then increases. After about 10 pore volumes have been displaced a second peak or shoulder appears at higher frequency. The noisiness of the response increases with time.

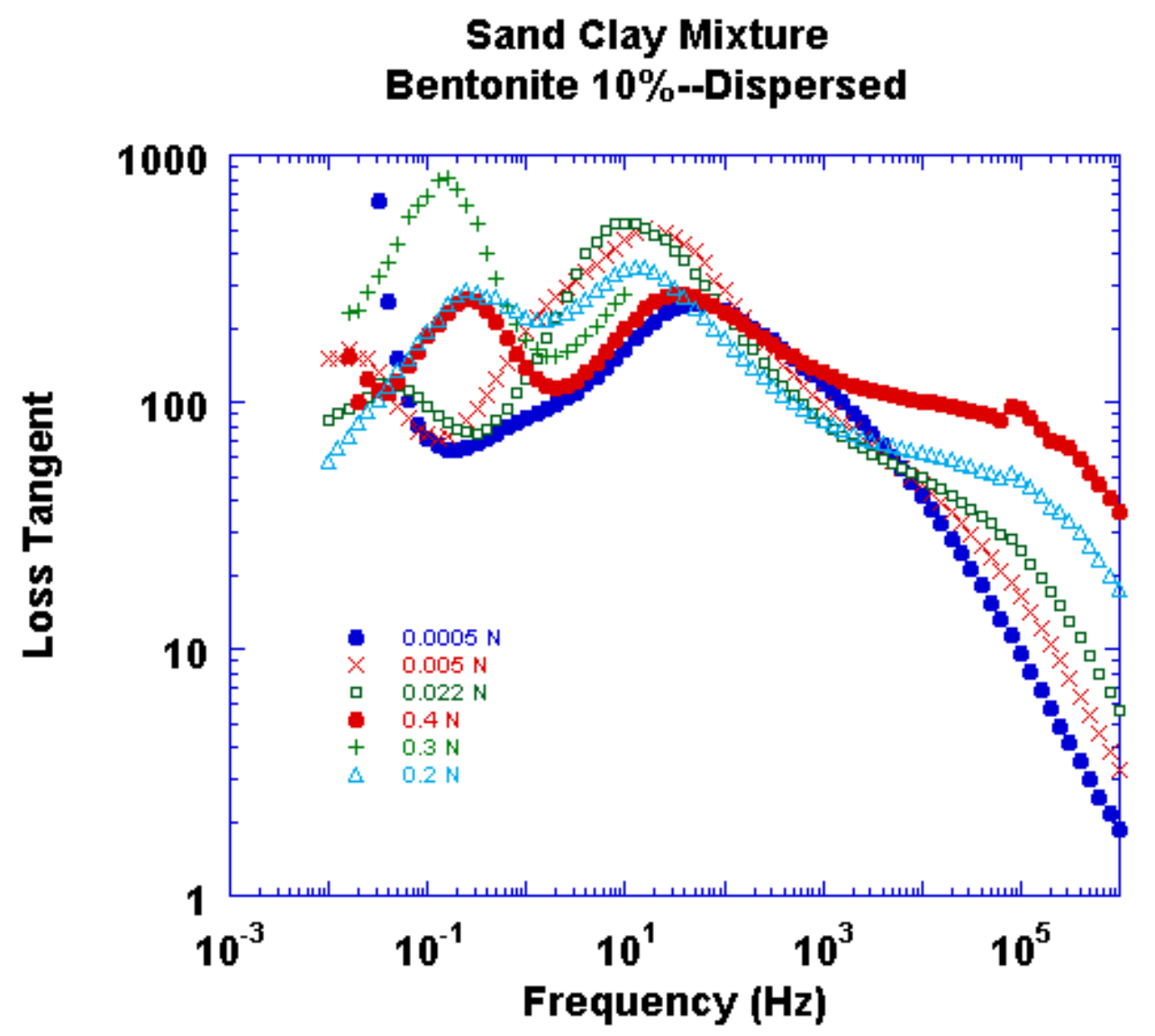

Figure 4. (a) Loss tangent vs frequency for dispersed-clay experiment. 


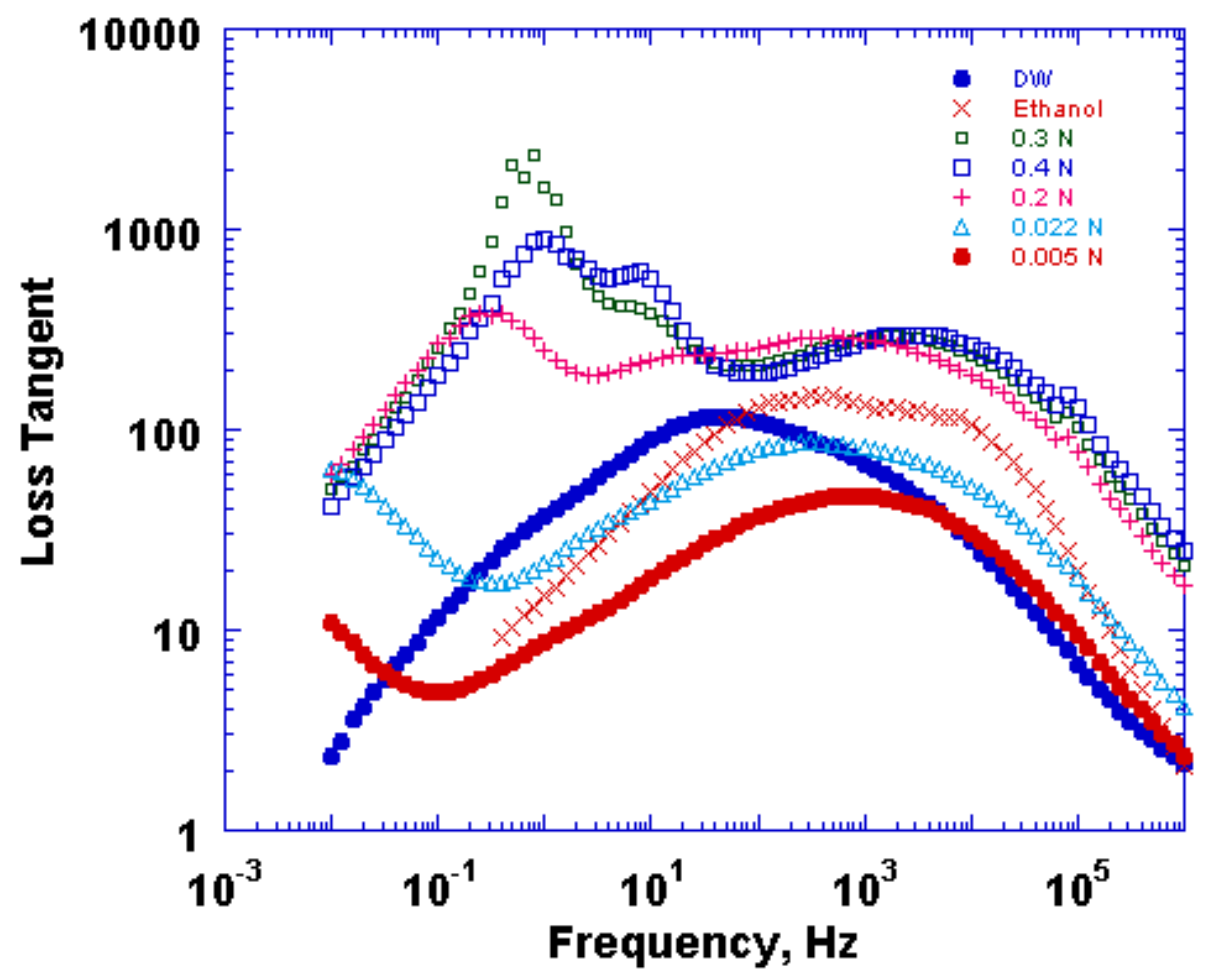

Figure 4. (b) Loss tangent vs frequency for parallel-clay experiment.

\subsection{X-Ray Images}

The parallel clay layer sample was x-rayed periodically during the ethanol-water flow portion of the experiment. Flow was stopped periodically and the sample was x-rayed to gain information about the thickness and integrity of the clay layer. The x-ray procedure is very similar to that described by Roberts and Lin (1997). A $160 \mathrm{kVp}$ linear source was used as the sample was rotated and translated vertically through the beam. A two-dimensional photo-diode linear array detector was used to convert and store the digital signal. The independent views (radiographs) were reconstructed into a series of tomographic slices. The information obtained is the attenuation of the sample as a function of time. Spatial resolution for this system was about $390 \mu \mathrm{m}$, although other systems in our laboratory can achieve spatial resolutions down to about $20 \mu \mathrm{m}$. Higher resolution scans will be required to image microcracks in the clay layer.

Reconstructed tomographic cross sections of the cylindrical sample are shown in Fig. 5a and 5b. In these gray-scale images a brighter shade is more attenuating than a darker shade. Figure 5a shows the sample prior to ethanol-water flow and Figure $5 \mathrm{~b}$ shows the sample after $\sim 10$ pore volumes of 80:20 ethanol-water have flowed through the sample. The samples are $\sim 5.08 \mathrm{~cm}$ diameter and each pixel is $\sim 390 \mu \mathrm{m} \times 390 \mu \mathrm{m}$. The primary feature to note is the thickness of the clay layer (gray vertical stripe in the center of the images) before and after flow. Although the spatial resolution of these images is insufficient to image cracking in the clay, it is easy to see the effect of dewatering. 

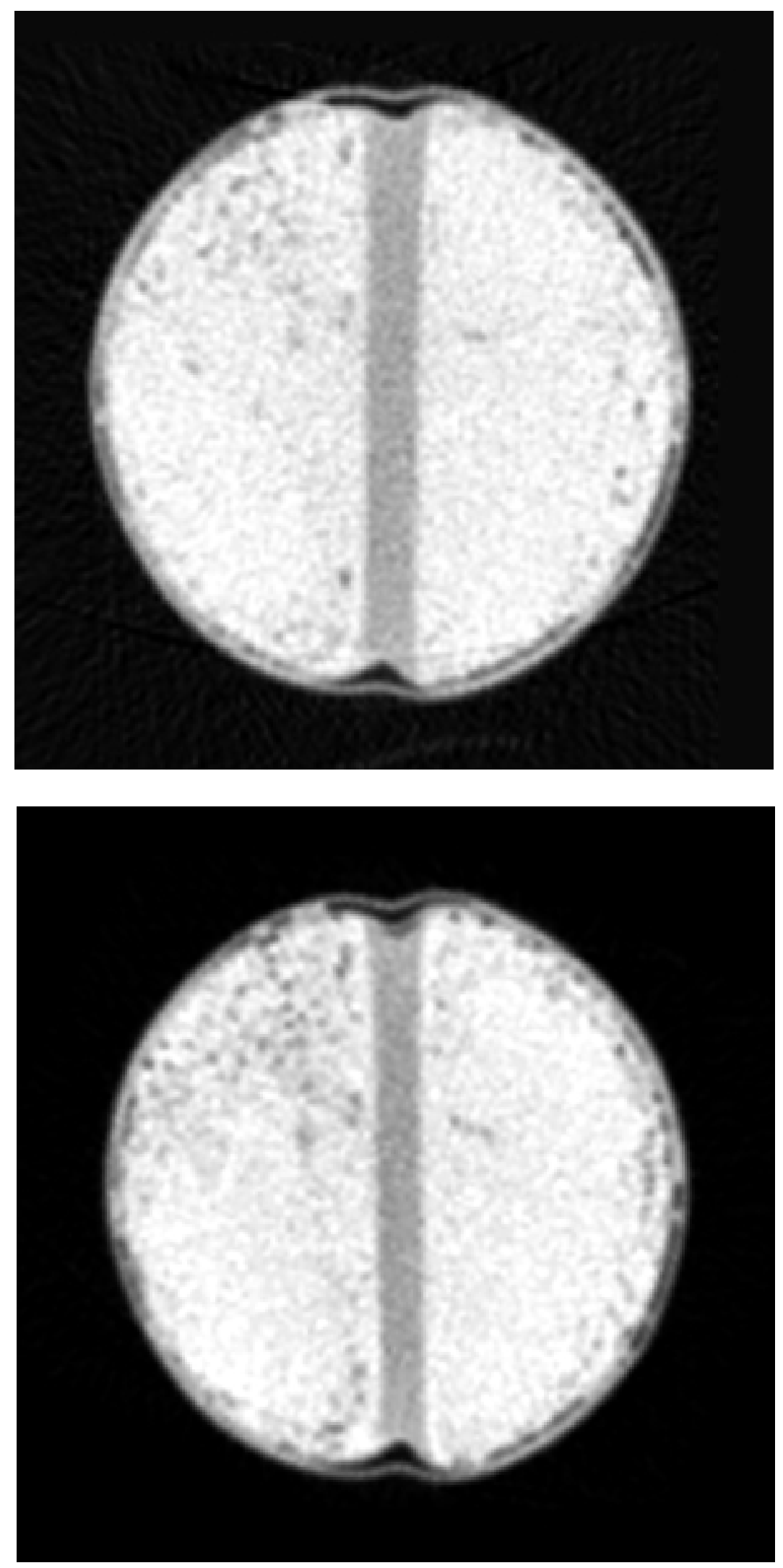

Figure 5. Reconstructed $x$-ray CT slices of the parallel clay layer sample (a) prior to ethanol-water flow and (b) after $\sim 10$ pore volumes of flow. Sample is $\sim 5.04 \mathrm{~cm}$ in diameter. 
Figures $6 \mathrm{a}$ and $6 \mathrm{~b}$ show averaged lines of attenuation across the clay layer (Fig. 6a, horizontal) and within the clay layer (Fig. 6b, vertical). Five lines were averaged for smoothing of data. The axes are distance and relative attenuation units. The curves are labeled sequentially from early in the experiment to later in the experiment and correlate to the amount of ethanol that has flowed through the sample. In Fig. 6a we see the width of the clay layer getting smaller and in Fig. $6 \mathrm{~b}$ we see the attenuation of the clay layer increasing with time and total flow. The thickness of the clay layer has changed by $25-40 \%$ with approximately ten pore volumes of fluid flow.
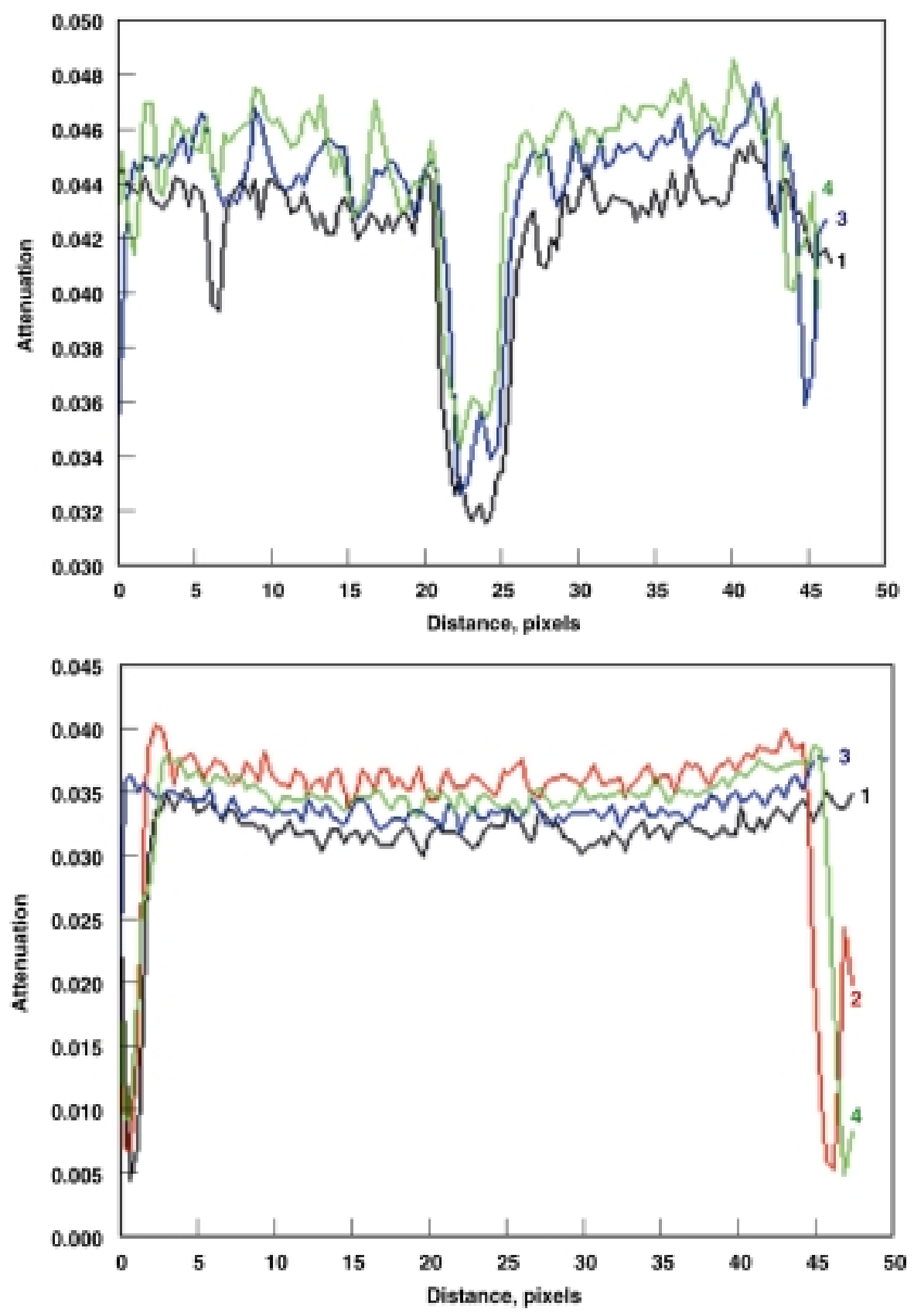

Figure 6. Relative attenuation vs distance across sample as a function of total flow and time for the parallel-clay layer sample using 80:20 ethanol-water as the pore fluid.

(a) Attenuation across the clay layer indicates a shrinking layer with time and flow.

(b) Attenuation within the clay layer shows increased attenuation with time and total flow. 


\section{Conclusions}

We have investigated the influence of 20 to $500 \mathrm{ppm}$ TCE on the complex impedance of sandclay samples. The presence of TCE had only a minor effect on the electrical resistivity. A more pronounced effect was observed in the loss tangent with a peak centered near $200 \mathrm{~Hz}$ that shifts to slightly lower frequency and decreases in height with the addition of TCE. Electrical experiments were performed on a sample containing a parallel clay layer while an ethanol-water mixture was displaced through the sample. Resistivity increased by as much as a factor of four as the ethanol-water mixture replaced the $0.022 \mathrm{~N} \mathrm{CaCl}_{2}$ solution. X-ray imaging during the dewatering experiment quantified the change in the clay layer which decreased in thickness by $\sim 33 \%$ with about 10 pore volumes of ethanol-water mixture flowed. Additional analyses using a higher spatial resolution x-ray system is needed to determine the presence and extent of microcracking in the clay due to dewatering.

\section{Acknowledgements}

This work was performed under the auspices of the U.S. Department of Energy by University of California LLNL under Contract Number W-7405-ENG-48 and supported specifically by the Environmental Management Science Program of the Office of Environmental Management and the Office of Energy Research. The following people are gratefully acknowledged for their assistance. E. Carlberg, D. Rikard, B. Ralph and C. Boro provided technical support. C. Talaber and T. Carey provided editorial assistance and B. Bonner provided stimulating discussion that helped this work.

\section{References}

Archie, G.E. (1942), “The Electrical Resistivity Log as an Aid in Determining Some Reservoir Characteristics," Trans. AIME, 146, 54-62.

Chan, C. Y., H. M. Buettner, R. Newmark, and G. Mavko (2000), "Conductivity Measurements of Sand-Clay Mixtures: A Modified Experimental Method," J. Env. and Engin. Geophys., 5, 15-26.

Dias, C. A. (2000), "Developments in a Model to Describe Low-Frequency Electrical Polarization of Rocks," Geophysics, 65, 437-451.

Glover, P.W.J., P.G. Meredith, P.R. Sammonds, and S.A.F. Murrell (1994), "Ionic Surface Electrical Conductivity in Sandstone," J. Geophys. Res., 99, 21635-21650.

Johnson, D.L., J. Koplik, and L.M. Schwartz (1986), "New Pore-Size Parameter Characterizing Transport In Porous Media," Phys. Rev. Lett, 57, 2564-2567.

Jones, D. P. (1997), “Investigation of Clay-Organic Reactions Using Complex Resistivity,” Ph.D. thesis, Colorado School of Mines.

Kostek, S., L.M. Schwartz, and D.L. Johnson (1992), "Fluid Permeability In Porous Media: Comparison Of Electrical Estimates With Hydrodynamical Calculations," Phys. Rev. B, 45,186-195.

Olhoeft, G.R. (1985), “Low-Frequency Electrical Properties,” Geophysics, 50, 2492-2503. 
Olhoeft, G. R. and T. V. V. King (1991), Mapping Subsurface Organic Compounds Noninvasively By Their Reactions With Clays, USGS Water Resources Investigation Report 91-4034.

Roberts, J. J., and W. Lin (1997), "X-Ray Radiography of Fracture Flow and Matrix Imbibition in Topopah Spring Tuff Under a Thermal Gradient," Int. J. Rock Mech. \& Min. Sci., 34:3-4, Paper No. 259.

Sen, P.N. and P.A. Goode (1992), "Influence of Temperature on Electrical Conductivity on Shaly Sands," Geophysics, 57, 89-96.

Sen, P.N., P.A. Goode, and A. Sibbit (1988), "Electrical Conduction In Clay Bearing Sandstones At Low And High Salinities,” J. Appl. Phys., 63, 4832-4840.

Ward, S. H., and G. W. Hohmann (1987), "Electromagnetic Theory for Geophysical Applications," in Electromagnetic Methods in Applied Geophysics, vol. 1, M. Nabighain, ed., Society for Exploration Geophysics, pp. 131-311.

Waxman, M.H. and L.J.M. Smits (1968), "Electrical Conductivities In Oil-Bearing Shaly Sands," Soc. Pet. Eng. J., 8, 107-122.

Wildenschild, D., J. J. Roberts, and E. D. Carlberg (1999), "Influence of Microstructural Properties on Geophysical Measurements in Sand-Clay Mixtures," Symposium on the Application of Geophysics to Engineering and Environmental Problems.

Wildenschild, D., J. J. Roberts and E. D. Carlberg (2000), "Electrical Properties of Sand-Clay Mixtures: The Effect of Microstructure," Geophys. Res. Lett., 27, 3085-3089. 